\title{
Medical Students' Perception and preferences on Methods of Anatomy Teaching- A survey between public and private institutes of Karachi, Pakistan
}

\author{
Munib Abbas \\ Karachi Medical \& Dental College, Pakistan \\ Shafaq Taseen \\ Karachi Medical \& Dental College, Pakistan \\ Syeda Sadia Masood Raza \\ Karachi Medical \& Dental College, Pakistan \\ Wajiha Waqar \\ Karachi Medical \& Dental College, Pakistan \\ Hina Khan \\ Karachi Medical \& Dental College, Pakistan
}

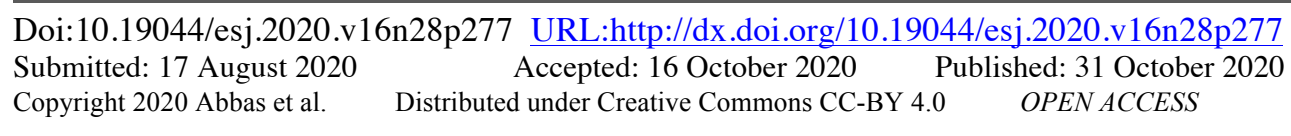

\begin{abstract}
Anatomy is an essential and basic subject in the field of human sciences. The reforms and new teaching methodologies has been revolutionizing the world and helping the student in better understanding the anatomical landmarks and specific details in an interactive way.

The present study evaluated the mode of anatomy teaching in public and private medical institutes of Karachi along with the opinion of students on the best teaching tool of anatomy. A total of 347 participants from private and public medical colleges of Karachi participated in the study. The data was collected by rotating questionnaires in the classrooms. Data was analyzed using Statistical Package for Social Sciences (SPSS) version 20. The mean age \pm SD of our sample was $19.10 \pm 0.77$ years. In this study, majority of students from private sector institute were satisfied (58\%) with the teaching methodology implemented for teaching Anatomy whereas, about (74\%) participants from public sector institutes were not satisfied with the teaching methodology of teaching Anatomy. Students recommended that the use of Anatomy models may help in their better understanding of Anatomy.

The present study indicates that public and private medical institutes were still using old multimedia based teaching methods of anatomy and the students were not very satisfied with
\end{abstract}


the mode of teaching in their institutes. Amendments and reforms shall be implemented and efficacious teaching techniques should be applied taking into consideration the opinion of the students to bring out the best understaning in the field of Anatomy.

Keywords: Anatomy, Teaching methodology, Medical students, teaching resources.

\section{Introduction}

Anatomy is one of the most essential and basic subjects in the field of medical education. Many of the other subjects are primarily based on the basis provided by the anatomy. Teaching Anatomy can be slightly different from various other human sciences subjects. It needs a particular method and appropriate tools such as atlases, cadavers, 3D animation models and various other e-learning tools (Gole et al., 2015). While talking about different teaching methods of anatomy, the traditional teaching method is based on giving lectures in front of a dense populated class, in this type of teaching method the students' needs to memorize a lot of new information and concepts without actually being able to relate and comprehend the given information (Mitchell et al., 2009; Moxham \& Plaisant, 2007). As a result, most of this concepts delivered in the lecture are either forgotten easily or the student may not have any interest in learning them which may result in poor understanding in the concepts of anatomy.

Medical students need critical understanding of anatomy, modification of its teaching methods makes it interesting for students to learn anatomy and on the other hand help them to improve their professional skills. The changes in teaching methodology and using advanced and modern methods of teaching may be effective for teaching and learning anatomy. It may also help improving students' attitudes towards the clinical importance and learning of anatomy (Gorgich et al., 2017).

With the changing world, the methods of teaching anatomy have been dramatically changed in 10 years. Gross anatomy teaching methodology and resources over these past years have changed and the advanced learning methods now used include cadaveric dissection, plastinated specimens, anatomical models, whereas surface anatomy is learned with painting the body for several anatomical land markings, reciprocal teaching methods and several other e-learning tools and platforms such as interactive multimedia and simulations (Sugand et al., 2010).

Considering these facts, and the reason that medical students need the knowledge of anatomy in their clinical courses, many innovative reforms have been made in the area of teaching (Gorgich et al., 2017; Moxham \& Plaisant, 2007). 
Mobile health (m-Health) devices and cellular applications (apps), can assist students to collect anatomical and physiological data for learning purposes (Gaglani \& Topol, 2014). Computer-assisted learning (CAL) resources have been included in anatomy courses (Azer \& Eizenberg, 2007) together with the dissection laboratory providing ease of time, place, and environment of learning (Johnson, 2013) Studies of medical students' inclinations for teaching and educational activities (TLA) highlights that "old-style" resources such as dissection, specimens, lectures, surface anatomy, workbooks, and diagrams are generally preferred over CAL resources.

Therefore, keeping in mind the importance of anatomy subject, this study is conducted to identify the point of view of medical students of the preclinical year regarding anatomy subject. This study aims to know the perception of students about the teaching methods used in anatomy among Public and Private sector medical universities. It further highlights the reforms suggested by them to enhance prevailing teaching methodologies, which can be applied to the institutions for better understanding of students.

\section{Methodology:}

This is a descriptive study which was conducted from September'19 to January'20 in various medical institues of Karachi, Sindh, Pakistan. A non-probablity convenience sampling technique was used to recruit the participants for the study. The participant were categorized based on the institues into two groups. Group A includes three medical institutes of Private setup (i.e. United Medical \& Dental College (UMDC), Jinnah Medical \& Dental College (JMDC) and Isra Medical College.) while Group $\mathrm{B}$ includes three medical institutes of Public setup (i.e. Dow University of Health Sciences (DUHS), Karachi Medical \& Dental College (KMDC) and Shaheed Mohtarma Benazir Bhutto Medical College Lyari (SMBBMC).

The sample size was calcualted uing following formulae:

$\mathrm{x}=\mathrm{Z}(\mathrm{c} / 100)^{2} \mathrm{r}(100-\mathrm{r})$

$\mathrm{N}=\mathrm{N} \mathrm{x} /\left[(\mathrm{N}-1) \mathrm{E}^{2}+\mathrm{x}\right]$

$\mathrm{E}=\mathrm{Sqrt}[(\mathrm{N}-\mathrm{n}) \mathrm{x} / \mathrm{n}(\mathrm{N}-1)]$

Where ' $\mathrm{N}$ ' is the population size, ' $\mathrm{r}$ ' is the fraction of responses. The total population of MBBS students in Group A of institutes was about a total of 300 students in 2nd-year MBBS (100 students per institute) among which sample size was calculated via a confidence level of $95 \%$ and confidence interval of about $6 \%$ which turned out to be of about 142 students. Whereas, the population of MBBS students in Group B of institutes was about a total 
of 700 students in 2nd-year MBBS (350 students in Dow, 250 in KMDC and 100 in SMBBMC) among which sample size was calculated via a confidence level of $95 \%$ and confidence interval of about $6 \%$ which turned out to be of about 194 students. Making a total population size of 336.

Around 465 self-structured questionnaires were rotated (Group A: 300, Group B: 165)

All individuals were in $2^{\text {nd }}$ year of MBBS, were aged 18 years or more and all had knowledge of English knowledge. Since anatomy is taught in only first two years of MBBS curriculum and from next year they will be going ahead towards their clinical clerkships, the study was conducted at the end of the academic year of when students have been taught most of their anatomy syllabus which makes them perfect candidates for study.

The questionnaire included demographic property (including age and gender) and questions inquiring about the teaching methodology in the institutes, and the preferred teaching methodology according to students and the mode of learning of Anatomy most prevalent among students were asked from the participants. The students are briefed about the questionnaire \& asked to respond freely without any sort of compulsion. Students were enlightened that the information provided by them is for the research and evaluation purposes only and will be confidential.

Data was collected and analyzed using Statistical Packaging for Social Sciences (SPSS-20). The frequency and percentage was calculated for the quantitative variables. Chi-square was applied and cut-off $p$-value of $<0.05$ was considered as significant.

\section{Results and Discussion}

Out of 465,347 students from $2^{\text {nd }}$ year MBBS ( $n=147$ for Group A; $\mathrm{n}=200$ for group B) participated in the study making a response rate of $74.62 \%$. The mean age \pm SD of our sample was $19.10 \pm 0.77$ years. More than half of the study population; $68.6 \%$ were female. $72.6 \%$ participants were from public sector whereas 27.4 were students of private sector.

Out of total 347 participants, 114 out of 147 participants (from Group A) and 186 out of 200 (from group B) claimed that multimedia was most commonly used to teach Anatomy in their institutes. The second most commonly used teaching method was found to be the use of Anatomy models (52.26\% of Group A and $46.26 \%$ of Group B). While the use of Anatomy Atlas, chalk board, Cadavers, Audio/Visual Aid, CBL/PBL and Histology-Practical were all found to be used at minimal. All the data depicted graphically in Fig 1. 


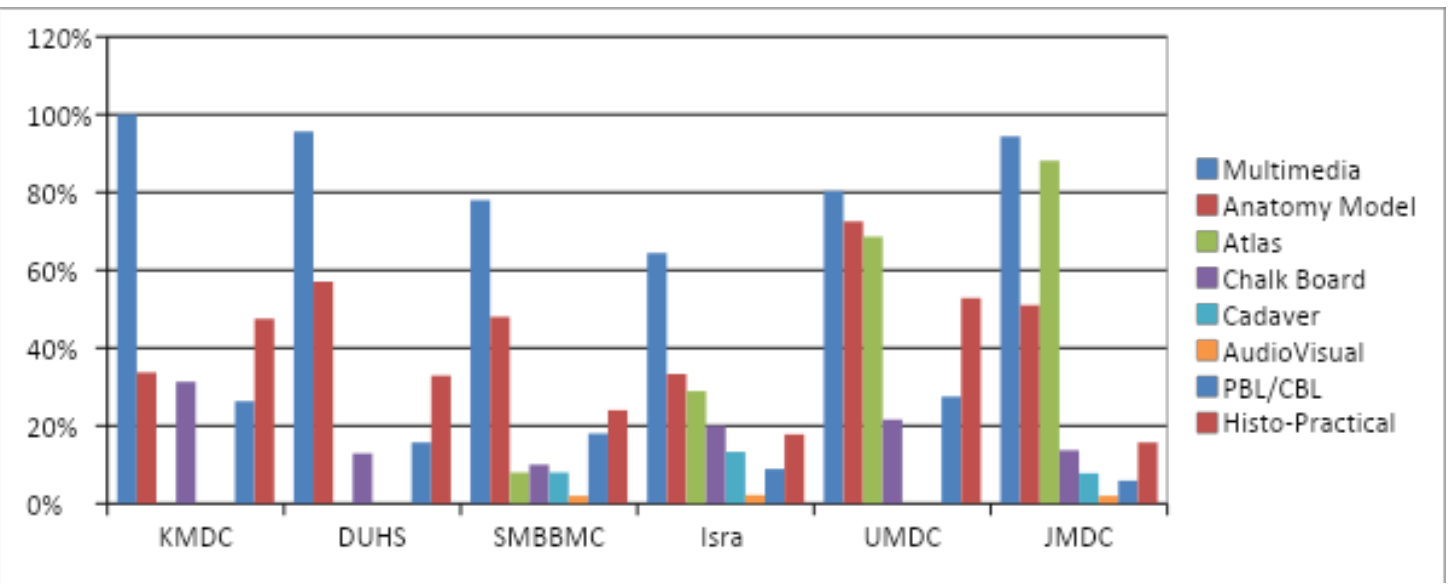

Fig 1: Generally practiced teaching methodology in various institutes.

Majority of students from private sector institute were satisfied (58\%) with the teaching methodology implemented for teaching Anatomy whereas, about $(74 \%)$ participants from public sector institutes were not satisfied with the teaching methodology of teaching Anatomy as shown in Figure 2.

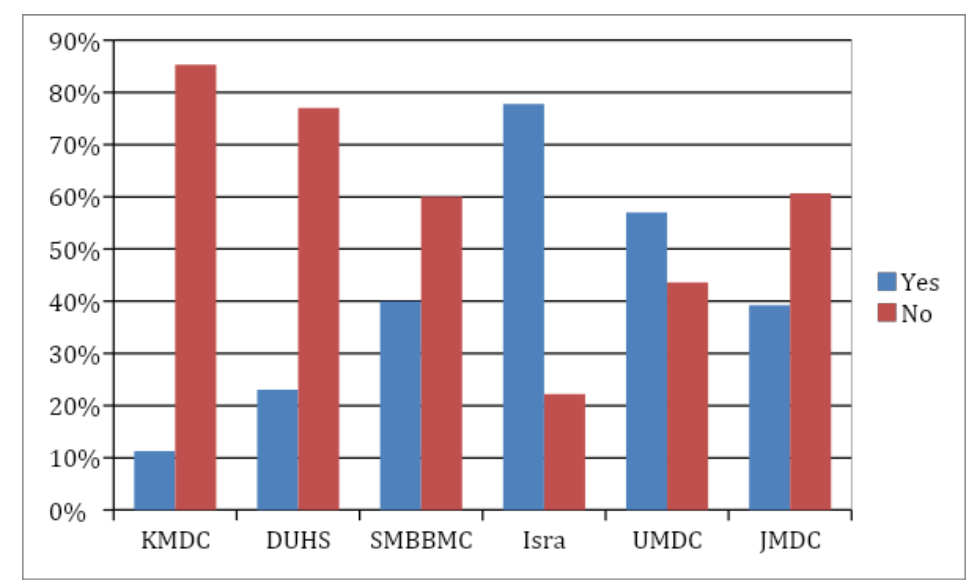

Figure 2: Opinion of students from various institutes on whether teachers are implementing the best methodology to teach Anatomy

Students recommended that the use of Anatomy method $(42.03 \%$ of Group A and 37.2\% of Group B) and Audio/visuals (21.86\% of Group A and $25.6 \%$ of Group B) may help in their better understanding of Anatomy. A minority of students also suggested that the use of chalk boards, multimedia, CBL/PBL sessions and Histology practical can help more in their understanding of Anatomy as represented in Figure 3. 


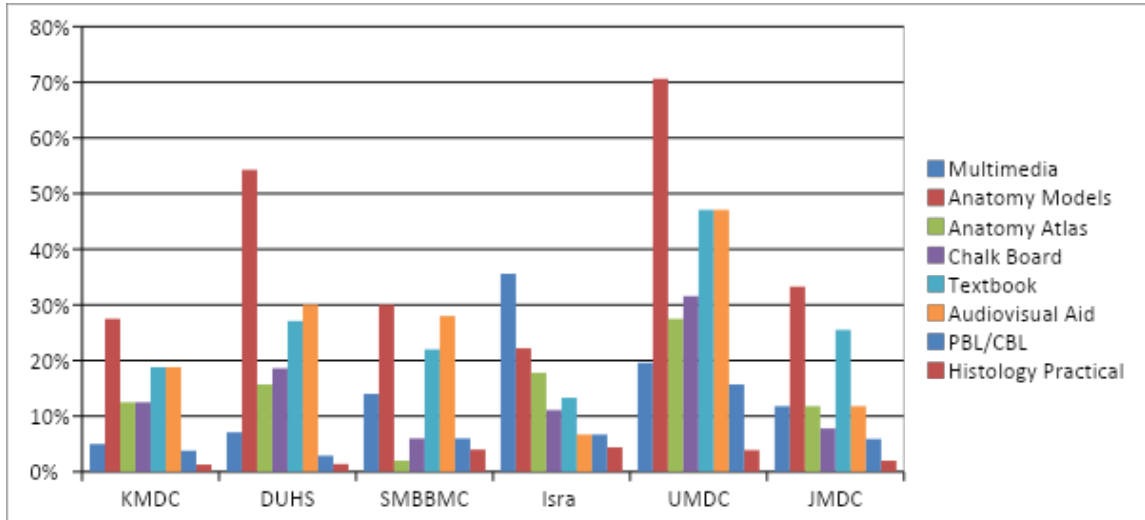

Fig 3: Opinion of students from various institutes about the best teaching methodology to seek a better understanding in Anatomy

Interactive teaching methodology and multimodal type of learning were the methods which may bring out the best outcome in learning Anatomy as recommended by majority of students from both private and public sector medical institutes. The other methods which may bring best outcome were multimedia teaching and case based reflective learning as shown in Table 1.

\section{Table 1:Opinion of students from Public and private institutes about teaching methodology that can bring the best outcome in learning Anatomy \\ (Chi-square value $=0.000)$}

\begin{tabular}{|c|c|c|c|c|c|c|}
\hline \multirow[t]{2}{*}{ Universities } & \multicolumn{3}{|c|}{ Public Institutes } & \multicolumn{3}{|c|}{ Private Institutes } \\
\hline & KMDC & DUHS & $\begin{array}{l}\text { SMBBM } \\
\mathrm{C}\end{array}$ & $\begin{array}{l}\text { Isra } \\
\text { Medical } \\
\text { College }\end{array}$ & UMDC & JMDC \\
\hline $\begin{array}{l}\text { Interactive } \\
\text { Teaching } \\
\text { (Frequency) --\% }\end{array}$ & (33)41.3 & (14)20.0 & (16)32.0 & (8) 17.8 & (15)29.4 & $(20) 39.2$ \\
\hline $\begin{array}{l}\text { Multimedia } \\
\text { teaching } \\
\text { method(Frequen } \\
\text { cy) --\% }\end{array}$ & (2) 2.5 & (8) 11.4 & (13)26.0 & (15)33.3 & (9)17.6 & (12)23.5 \\
\hline $\begin{array}{l}\text { Practical/ case } \\
\text { based } \\
\text { reflection(Freque }\end{array}$ & (9)11.3 & (18)25.7 & (10)20.0 & (10)22.2 & (7)13.7 & (9)17.6 \\
\hline
\end{tabular}




\begin{tabular}{|c|c|c|c|c|c|c|}
\hline \multicolumn{7}{|l|}{ ncy) --\% } \\
\hline $\begin{array}{l}\text { Multimodal } \\
\text { teaching } \\
\text { (Frequency) --\% }\end{array}$ & (23)28.7 & $(25) 35.7$ & (9)18.0 & (10)22.2 & (20)39.2 & (8) 15.7 \\
\hline $\begin{array}{l}\text { Others } \\
\text { (Frequency) --\% }\end{array}$ & (13)16.3 & $(5) 7.1$ & (2) 4.0 & (2) 4.4 & 0 & (2)3.9 \\
\hline $\begin{array}{l}\text { Total (Frequency) } \\
--\%\end{array}$ & $(80) 100$ & $(70) 100$ & (15)100 & $(45) 100$ & (51)100 & (51)100 \\
\hline
\end{tabular}

Majority of participants of the study were of the view that decrease in number of lectures and increase in demos can lead to a better and firm understanding of Anatomy. Moreover, students suggested that additional time shall be allocated for dissection/tutorial anatomy classes (table 2)

Table 2: Opinion of students from Public and private institutes about reforms that can produce better understanding in learning anatomy.

(Chi-square $=\mathbf{0 . 0 0 0})$

Universities

\section{Decrease number} of lectures and increase number of demos

(Frequency) --\% Increase number of lectures

(Frequency) -\% Additional time for dissection/tutoria Is

(Frequency) --\% Good as they are (Frequency) --\%

Total
Public Institutes

KMDC DUHS

$$
\text { C }
$$

C

Private Institutes

Medical

College
(33) 41.3
(47)67.1
(15)30.0
(6)13.3
(11)21.6
(16)31.4
(7) 8.8
(4)5.7
(11) 22.0
(16)35.6
(8) 15.7
(6) 11.8 
Despite various advances in the field of teaching and medical sciences, the study found out that many institutes were still using old and traditional teaching methods. The use of multimedia was common in many institutes because on one hand it is feasible and easy to use whereas on the other hand, it eradicate many deficiency which were previously faced in teaching and learning Anatomy and it is also the best possible way to teach keeping in mind the shortage of cadavers and computer-assisted learning devices in health education (Hafeez, 2012).

Interactive and multimodal teaching methods can be beneficial in learning of anatomy as suggested by our participants, this can be backup by another study in which didactic lectures were taken for a specific organ system, after the lecture a test was conducted to access the understanding of pupil regarding that organ system that was taught, the test contained clearly defined short clinical problems. A vast majority of students specified that a combination of didactic lectures and case-oriented learning can be beneficial in relating clinical condition with the basic anatomical mechanism (Ghosh, 2007). According to another study, group study is a very strong tool in the learning aspects of the medical field. Team-based learning (TBL) is a way of incorporating interactive learning which has been proved to be very effective. TBL emphasizes on teamwork, and problem solving for clinical assessment. Medical schooling institutes are building incorporated and interdisciplinary courses through the preclinical years. TBL proves to be a good strategically tool in memorizing gross anatomy (Vasan et al., 2009). The nature and role of teacher is of fundamental importance in integrating the advanced technology and simplifying the material and strengthening the concepts to apply them in solving problems (Hafeez et al., 2014) which might be the reason behind dissimilarity between Group B and Group A, about their opinion on level of satisfaction in the current teaching methodology.

The use of Anatomy models in learning of anatomy was appreciated by majority of participants of the study which can be supported by a study that pointed out that students preferred the $3 \mathrm{D}$ anatomy models as an efficient learning tool than traditional teaching, textbooks, and lectures (Azer \& Azer, 2016). On the other hand, visual information is a useful aid and benefits in retaining and learning the concepts and relations of various anatomical sites, visual aid also helps in building a much healthier long-term memory on any given topic. E-learning platforms are also essential in this regard, in all areas of medical learning, this modality has a greater perspective. The construction of high-quality visuals is essential in the 
teaching of Anatomy as it is an eloquent field with a highly visual-oriented discipline (Khan et al., 2015). The implementation of multimodal learning methodology provides enhancement and stimulation of learning for all the students (Drake \& Pawlina, 2014). It has also been documented to boost the performance and self-confidence of students while appearing in an examination and enhance the deep learning with integration of anatomy and real-life clinical context (Nicholson et al., 2016).

Participants of the study also pointed out that the duration of lectures shall be decreased and number of demos to be increased; this result may reflect the findings of a study in which it was highlighted that any learning will fail if there is solely the transfer of knowledge from teacher to students without any interaction among (Ahmed \& Carvalho, 2014). The second suggestion made was to give additional time for dissection/tutorials by the greatest percentage of students after all, effective teaching is one in which the learner absorbs the most, and it is not about just a PowerPoint presentation provided by a professor (Mazur, 1997). The opinion of students holds a supreme spot in the way of how they grasp the core contents of the subject and what is lacking in fulfilling their target.

Effective and simplified learning and teaching of anatomy is of core importance because the basic anatomy of human body goes hand in hand with safe and better medical practice. Due to declining depth in time allocation for anatomy, a large multitude of many reported anatomical errors can be seen globally in medical professionals (Turney, 2007).

\section{Limitations of the study}

The study is limited to six medical (three Publics and three private) institutes of Karachi which restrict the generalization of our findings.

A similar study in comparable cities or countries needs to be conducted in future to validate the result and to add further insights about teaching methodologies in medical institutes.

\section{Conclusion}

The present study evaluated the teching methodology of Anatomy in public and private institutes of Karachi,Pakistan with the help of survey based methodology; results indicates that public and private medical institutes were still using old multimedia based teaching methods of anatomy which might not prove to be effective in better and effective learning of Anatomy. The students, particularly from public sector institues were not very satisfied with the mode of teaching in their institute.

It can be concluded that the medical institues in Karachi requires reforms and amendments of the curriculum regarding current anatomy teaching practices. This study proposes that bringing revolutionary and efficacious teaching 
methodology techniques should be applied taking into consideration the opinion of the students to bring out the best in them.

\section{References:}

1. Sugand, K., Abrahams, P., \&Khurana, A. (2010). The anatomy of anatomy: a review for its modernization. Anatomical sciences education, 3(2), 83-93. https://doi.org/10.1002/ase.139

2. Gaglani, M. S. M., \&Topol, E. J. (2014). iMedEd: the role of mobile health technologies in medical education. Academic medicine: journal of the Association of American Medical Colleges, 89(9), 1207. https://doi.org/0.1097/ACM.0000000000000361

3. Azer, S. A., \&Eizenberg, N. (2007). Do we need dissection in an integrated problem-based learning medical course? Perceptions of first-and second-year students. Surgical and Radiologic Anatomy, 29(2), 173-180. https://doi.org/10.1007/s00276-007-0180-x

4. Johnson, G. B. (2013). Student perceptions of the flipped classroom (Doctoral dissertation, University of British Columbia). https://dx.doi.org/10.14288/1.0073641

5. Gole, R. A., Meshram, P., \&Hattangdi, S. (2015). Changes in perception about anatomy subject after 1 st year of medical course. India J Basic Appl Med Res, 4(4), 453-57.

6. Mitchell, B. S., Xu, Q., Jin, L., Patten, D., \&Gouldsborough, I. (2009). A cross cultural comparison of anatomy learning: Learning styles and strategies. Anatomical sciences education, 2(2), 49-60. https://doi.org/10.1002/ase.73

7. Moxham, B. J., \&Plaisant, O. (2007). Perception of medical students towards the clinical relevance of anatomy. Clinical Anatomy: The Official Journal of the American Association of Clinical Anatomists and the British Association of Clinical Anatomists, 20(5), 560-564. https://doi.org/10.1002/ca.20453

8. Gorgich, E. A. C., Sarbishegi, M., Barfroshan, S., \&Abedi, A. (2017). Medical students knowledge about clinical importance and effective teaching methods of anatomy. Shiraz E-Medical Journal, 18(12), e14316. https://doi.org/10.5812/semj.14316

9. Reidenberg, J. S., \&Laitman, J. T. (2002). The new face of gross anatomy. The Anatomical Record: An Official Publication of the American Association of Anatomists, 269(2), 81-88. https://doi.org/10.1002/ar.10076

10. Hafeez, A. (2012). Is the use of PowerPoint presentations a better tool of understanding gross anatomy than cadaveric dissection?. Ann. Pak. Inst. Med. Sci, 8(1), 6-10. 
11. Ghosh, S. (2007). Combination of didactic lectures and case-oriented problem-solving tutorials toward better learning: perceptions of students from a conventional medical curriculum. Advances in Physiology Education. https://doi.org/10.1152/advan.00040.2006

12. Hafeez, K., Khan, M. L. U. Z., Jawaid, M., \& Haroon, S. (2014). Low attendance in lectures at medical colleges of Karachi-A cross sectional survey. Journal of Postgraduate Medical Institute (Peshawar-Pakistan), 28(2).

13. Azer, S. A., \&Azer, S. (2016). 3D anatomy models and impact on learning: a review of the quality of the literature. Health professions education, 2(2), 80-98. https://doi.org/10.1016/j.hpe.2016.05.002

14. Khan, M. S. G., ul Ain, Q., Hussan, S. I., Basher, S., Iram, H., \& Umar, B. (2015). Opinion of Pakistani physiotherapists/students about anatomy as a subject and method of teaching anatomy: A cross sectional survey. JPMA The Journal of the Pakistan Medical Association, 65(2), 153-155.

15. Vasan, N. S., DeFouw, D. O., \& Compton, S. (2009). A survey of student perceptions of team based learning in anatomy curriculum: Favorable views unrelated to grades. Anatomical sciences education, 2(4), 150-155. https://doi.org/10.1002/ase.91

16. Drake, R. L., \&Pawlina, W. (2014). Multimodal education in anatomy: The perfect opportunity. Anatomical sciences education, 7(1), 1-2. https://doi.org/10.1002/ase.1426

17. Nicholson, L. L., Reed, D., \& Chan, C. (2016). An interactive, multimodal Anatomy workshop improves academic performance in the health sciences: a cohort study. BMC medical education, 16(1), 7. https://doi.org/10.1186/s12909-016-0541-4

18. Ahmed, S., \&Carvalho, H. (2014). The art of demonstration in anatomy instruction. Revista Hospital Universitário Pedro Ernesto, 13(4). https://doi.org/10.12957/rhupe.2014.13947

19. Mazur, E. (1997, March). Peer instruction: Getting students to think in class. In AIP Conference Proceedings (Vol. 399, No. 1, pp. 981988). American Institute of Physics. https://doi.org/10.1063/1.53199

20. Gulnaz, H. U. M. A. I. R. A., Mujtaba, G., Baig, V., \& Khalid, S. (2018). Shortcomings of Current Anatomy Teaching Methodologies in Medical Schools and Possible Avenues of Improvement: A comparative study between undergraduates, postgraduate students and teaching faculty. Pakistan Journal of Medical and Health Sciences, 12(2), 558-560.

21. Turney, B. W. (2007). Anatomy in a modern medical curriculum. The Annals of The Royal College of Surgeons of England, 89(2), 104-107. https://doi.org/10.1308/003588407X168244 